\title{
Analisa Stabilitas Transien Pada Sistem Transmisi Sumatera Utara 150 kV - 275 kV Dengan Penambahan PLTA Batang Toru $4 \mathrm{X}$ $125 \mathrm{MW}$
}

\author{
Danar Tri Kumara, Prof. Ir Ontoseno Penangsang M.Sc,Ph.D, dan Ir. NI Ketut Aryani, MT \\ Jurusan Teknik Elektro, Fakultas Teknilogi Industri, Institut Teknologi Sepuluh Nopember (ITS) \\ Jl. Arief Rahman Hakim, Surabaya 60111 Indonesia \\ e-mail: ontosenop@ee.its.ac.id, ketut.aryani@gmail.com, dtk_kumara@yahoo.co.id.
}

\begin{abstract}
Abstrak- Sistem kelistrikan Sumatera Utara yang dipasok dengan menggunakan sistem Transmisi $150 \mathrm{kV}$ dan $275 \mathrm{kV}$ merupakan sistem transmisi dengan pusat beban terbesar di Sumatera. Dalam upaya memenuhi kebutuhan listrik, sesuai dengan RUPTL, Sistem Transmisi Sumatera Utara akan mengoperasikan PLTA Batang Toru dengan kapasitas 4 x 125 MW pada tahun 2020. Karena potensi sumber energi yang cukup besar di Sumatera Utara adalah tenaga air dan panas bumi. Dengan penambahan PLTA Batang Toru 4 x 125 MW, perlu dilakukan studi kestabilan transien untuk mengetahui kestabilan sistem saat terjadi gangguan transien. Dari hasil simulasi menunjukkan bahwa case lepasnya generator, lepasnya satu saluran dan saluran ganda tidak menyebabkan sistem keluar dari batas stabil. Karena ketika generator lepas, daya supply yang hilang hanya 5-8\% dari total pembangkitan. Begitu juga dengan kasus single pole auto reclosing dengan waktu Circuit Breaker kembali tertutup sebesar $500 \mathrm{~ms}$ setelah gangguan, hasil respon sudut rotor, frekuensi dan tegangan menunjukkan sistem masih stabil. Pada penentuan waktu pemutusan kritis (CCT), nilai CCT pada sistem 2018 dapat ditemukan pada 120 ms - 140 ms (batas rekomendasi CCT sistem besar). Sedangkan pada sistem 2020 tetap dalam keadaan stabil ketika terjadi gangguan hubung singkat 3 fasa . Sehingga penentuan CCT (Critical Clearing Time) melebihi dari batas rekomendasi nilai CCT untuk sistem besar.
\end{abstract}

Kata Kunci- kestabilan transien, generator lepas, saluran lepas, single pole auto reclosing, critical clearing time.

\section{PENDAHULUAN}

Sistem tenaga listrik yang baik adalah sistem tenaga listrik yang mampu melayani beban secara kontinyu, tegangan dan frekuensi yang konstan, fluktuasi tegangan dan frekuensi yang terjadi harus berada pada batas toleransi yang diizinkan. Hal ini agar peralatan listrik konsumen dapat bekerja dengan baik dan aman. Karena perubahan beban yang bervariasi akan berdampak pada kestabilan sistem. Perubahan yang signifikan dapat menyebabkan sistem keluar dari batas stabil. Oleh karena itu perubahan beban harus diikuti perubahan daya penggerak generator. Hal ini dimaksudkan agar terjadi keseimbangan antara daya beban dan daya suplai. Sehingga frekuensi dan tegangan sistem tetap terjaga pada posisi normal.

Untuk memperjelas bahasan pada tugas akhir ini perlu adanya pembatasan masalah. Adapun batasan tersebut meliputi :

1. Analisa kestabilan Transient di Sumatera Utara dilakukan dengan memperhatikan sudut rotor generator, frekuensi dan tegangan pada bus

2. Gangguan yang dianalisa adalah efek transien dikarenakan generator lepas, 1 line trip, 2 line trip, auto single pole reclosing, dan critical clearing time dengan masing masing gangguan diambil 1 case dari setiap tahunnya.

3. Software bantu yang digunakan adalah ETAP 12.6.

\section{KESTABILAN SISTEM TENAGA}

\section{A. Kestabilan Sistem Tenaga}

Kestabilan sistem tenaga listrik secara luas dapat didefinisikan sebagai kemampuan dari satu sistem tenaga listrik untuk tetap berada dalam kondisi seimbang dalam operasi normal dan dapat memperoleh kembali kondisi seimbang setelah sistem mengalami gangguan.

Berdasarkan Paper IEEE definition and classification of power system stability, kestabilan sistem tenaga listrik dibagi menjadi tiga kategori yaitu [4]:

1. Kestabilan sudut rotor [2]

Kestabilan sudut rotor adalah kemampuan dari beberapa mesin sinkron yang saling terinterkoneksi pada suatu sistem tenaga untuk mempertahankan kondisi sinkron.

2. Kestabilan frekuensi [4]

Kestabilan ini berkaitan dengan kemampuan dari sistem untuk mempertahankan kestabilan frekuensi akibat gangguan pada sistem yang mengakibatkan ketidakseimbangan antara pembangkitan dan beban.

3. Kestabilan tegangan [4]

Kestabilan tegangan dapat diartikan sebagai kemampuan dari sistem tenaga listrik untuk mempertahankan kestabilan nilai tegangannnya di semua bus pada sistem dalam kondisi operasi normal maupun setelah terjadi gangguan.

\section{B. Stabilitas Transien}

Kestabilan Transien adalah kemampuan dari suatu sistem tenaga untuk mempertahankan sinkronisasi setelah mengalami gangguan besar yang bersifat mendadak dalam waktu satu 
swing yang pertama. Dengan asumsi pengatur tegangan otomatis (AVR) dan Governor belum bekerja.

\section{Dinamika Rotor dan Persamaan Ayunan}

Persamaan yang mengatur gerakan rotor suatu mesin serempak didasarkan pada prinsip dasar dinamika yang menyatakan bahwa momen putar percepatan (accellerating torque) adalah hasil kali dari momen-momen kelembaman (moment of inertia) rotor dan percepatan sudutnya. Dalam sistem unit-unit $M K S$ dan untuk generator serempak, persamaan ini dapat ditulis dalam bentuk [3]:

$$
J \frac{d^{2} \theta_{m}}{d t^{2}}=T_{a}=T_{m}-T_{e}
$$

Simbol-simbol pada persamaan 2.15 mempunyai arti sebagai berikut:

$J=$ Momen kelembaman total dari massa rotor dalam $\mathrm{kg}$ $m^{2}$

$\theta_{m}=$ Pergeseran sudut dari rotor terhadap suatu sumbu yang diam (stationary), dalam radian mekanis

$t=$ Waktu, dalam detik

$T_{a}=$ Momen putar percepatan bersih, dalam $\mathrm{Nm}$

$T_{m} \quad=$ Momen putar mekanis atau poros (penggerak) yang diberikan oleh penggerak mula dikurangi dengan momen putar perlambatan (retarding) yang disebabkan oleh rugirugi perputaran, dalam $\mathrm{Nm}$

$T_{e}=$ Momen putar elektris atau elektromagnetis bersih, dalam $\mathrm{Nm}$

Faktor yang mempengaruhi stabilitas transien [2]

1. Seberapa besar generator tersebut dibebani

2. Output generator selama gangguan. Ini tergantung dari lokasi gangguan dan type gangguan.

3. Waktu pemutusan gangguan.

4. Reaktansi sistem transmisi setelah gangguan.

5. Reaktansi generator. Reaktansi yang rendah meningkatkan daya puncak.

6. Inersia generator. Inersia yang besar, menyebabkan perubahan sudut lambat. Ini menurunkan energi kinetik yang diperoleh saat gangguan.

\section{SISTEM KELISTRIKAN TRANSMISI SUMATERA UTARA DAN ALUR PENGERJAAN}

Sistem kelistrikan di Sumatera Utara dipasok dengan menggunakan sistem transmisi $150 \mathrm{kV}$,dan $275 \mathrm{kV}$. Namun secara umum sistem transmisi yang digunakan adalah $150 \mathrm{kV}$. Saluran antar bus menggunakan sistem double circuit ( 2 saluran ) dan single circuit. Untuk saluran yang menghubungkan bus dengan kapasitas pembangkit yang besar menggunakan sistem double circuit dengan tujuan menjaga kontinyuitas penyaluran daya listrik ketika salah satu bermasalah (terjadi gangguan). Maka daya listrik masih dapat disalurkan meskipun tidak $100 \%$ dari kondisi awal.

Sistem kelistrikan Sumatera Utara terdiri atas 72 bus dengan 104 saluran dan 26 pembangkit untuk tahun 2018 ( sebelum masuknya PLTA Batang Toru 4 x $125 \mathrm{MW}$ ). Untuk tahun 2020 ( saat masuknya PLTA Batang Toru) terdiri atas
74 bus dengan 108 saluran dan 33 pembangkit. Kondisi tersebut merupakan kondisi peak ( beban puncak ). Untuk kondisi light ( beban dasar ) tentunya memliki nominal yang lebih kecil untuk pembangkit yang dioperasikan. (akan diperjelas di tabel data Pembangkit). Adapun pembangkit PLTGU Belawan dan PLTU Pangkalan Susu bertindak sebagai swing, dan pembangkit - pembangkit lainnya bertindak sebagai voltage control.

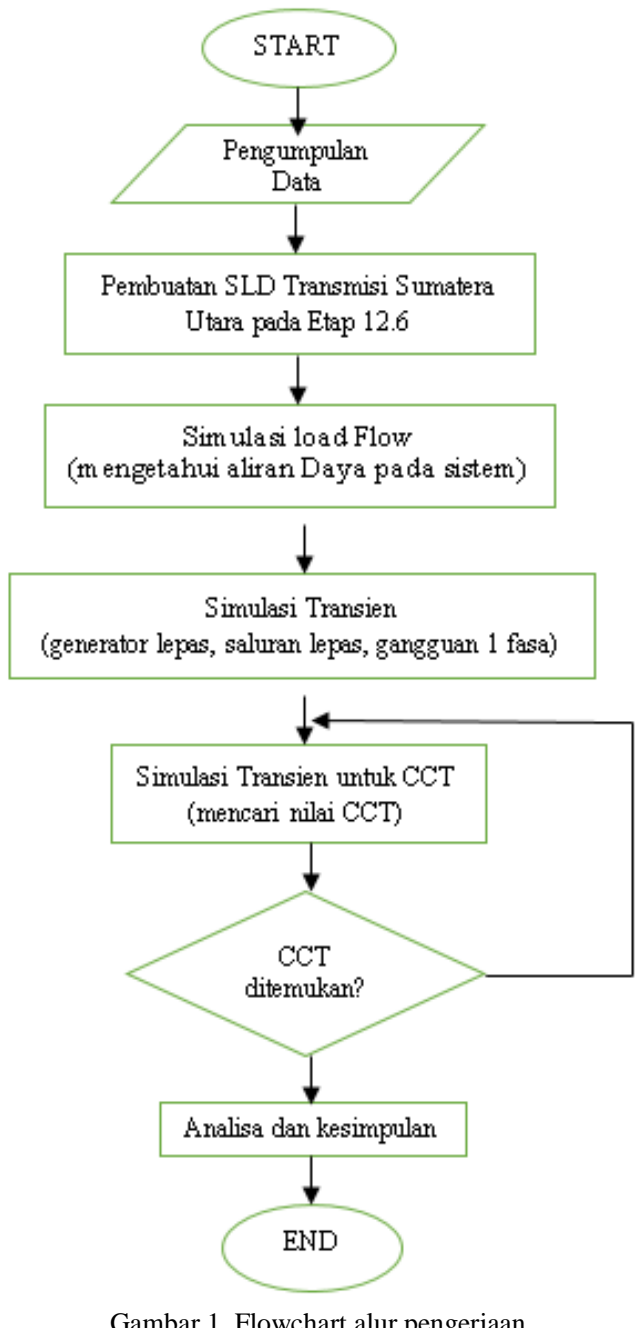

IV. SIMULASI DAN ANALISIS

Setelah melakukan pemodelan Single Line diagram di ETAP 12.6, selanjutnya akan dilakukan simulasi stabilitas transien yang meliputi lepasnya Generator, lepasnya single line dari double line, lepasnya double line, gangguan satu fasa dan lepasnya single line dari double line dengan kembalinya recloser, dan gangguan hubung singkat untuk menentukan nilai Critical Clearing Time (CCT) .Untuk lebih jelasnya, kasus yang akan dianalisa adalah seagai berikut :

\section{No-Fault Tripping of The Largest On-Line Generating Unit}

Pada kasus ini, dilakukan pemadaman pada generator terbesar pada saat terhubung pada sistem Sumatera Utara. Generator dengan kapasitas terbesar akan off sedangkan generator pembangkit lain aktif. 


\section{No-Fault One-Circuit Tripping of the Double-Circuit Interconnection Transmission Line}

Pada kasus ini satu saluran dari saluran ganda yang memiliki aliran daya terbesar lepas (kehilangan transfer daya) tanpa gangguan.

\section{No-Fault Double-Circuit Tripping of Interconnection Transmission Line}

Pada kasus ini saluran ganda yang memiliki aliran daya terbesar lepas (kehilangan transfer daya) tanpa gangguan.

\section{Single Pole Auto Reclosing}

Pada kasus ini terjadi hubung singkat 1 fasa ke tanah di bus. Kemudian diikuti oleh lepasnya satu saluran (one circuit)dari saluran ganda. setelah itu satu saluran yang lepas kembali lagi ke saluran ganda.

\section{Critical Clearing Time (CCT)}

Pada kasus ini terjadi hubung singkat 3 fasa di bus kemudian dicari waktu pemutusan kritisnya dengan membuka nya $\mathrm{CB}$ pada saluran bus tersebut

\section{A. Sinulasi Kasus 1}

Pada kasus ini, PLTA Asahan 3-1 yang memiliki kapasitas 174 MW dan dioperasikan sebesar 140 MW sebagai voltage control akan trip. Daya keseluruhan kapasitas pembangkit adalah 3122,5 MW dan kebutuhan beban sebesar 2402,57 MW. Hasil simulasi ketika PLTA Asahan 3-1 trip sebagai berikut :

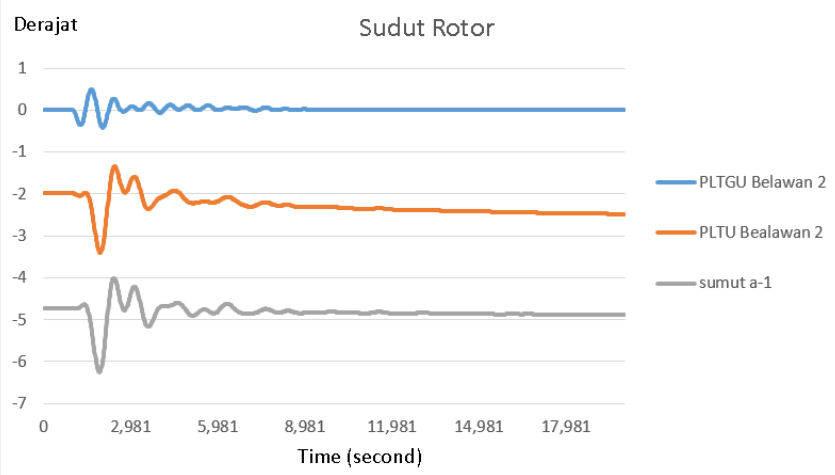

Gambar 2 Respon sudut Rotor Generator ketika PLTA Asahan 3-1 (2018 peak load) trip

Pada tahun 2018 peak load ,PLTA Asahan beroperasi paling besar dari pada generator lainnya. Dengan hilangnya PLTA Asahan 3-1 maka sistem kehilangan sebesar 5,8\% daya supply dari sistem 2018 beban puncak. Namun Sudut Rotor pada beberapa generator yang ditampilkan masih berada pada batas stabil. Pada gambar di atas (Generator Sumut a-1), osilasi sudut rotor hanya sampai 6 derajat dan steady state pada 5 derajat. Selama masih bisa kembali steady state di bawah 90 degree maka masih dalam batas stabil. Perubahan sudut rotor ini dapat dipengaruhi oleh beberapa faktor. Salah satu di antaranya pembebanan generator, inersia, dan damping dari masing - masing generator. Geerator yang memiliki damping yang besar akan cenderung lebih stabil jika terjadi gangguan dan sebaliknya.

\section{B. Simulasi Kasus 2}

Nilai aliran daya terbesar yang mengalir pada saluran transmisi Sumatera Utara 2018 untuk kasus beban dasar berada di saluran 89 yaitu antara bus P. Brandan - bus

Pangkalan Susu sebesar 473,05 MW. Pada simulasi transien ini satu saluran dari saluran ganda lepas tanpa adanya gangguan. Untuk hasil simulasinya sebagai berikut

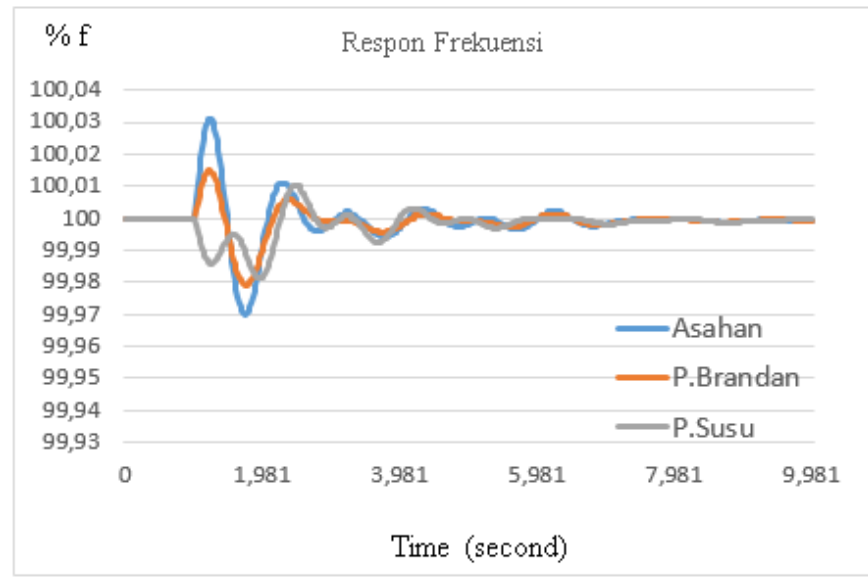

Gambar 3 Respon frekuensi pada bus ketika saluran 89 lepas (2018 - light load)

Dari hasil simulasi di atas, hilangnya satu saluran tidak berdampak besar pada kestabilan sistem Transmisi Sumatera Utara khususnya pada frekuensi bus. Ketika saluran tunggal lepas, osilalasi yang terjadi hanya $0,03 \%$. Setelah itu respon frekuensi dapat kembali dengan cepat pada $100 \%$. Kita ketahui bahwa batas stabil untuk frekuensi adalah 100,83\% dan 99,17\%. Jadi sistem Transmisi Sumatera Utara masih berada pada batas stabil ketika terjadi gangguan satu saluran lepas pada saluran ganda.

\section{Simulasi Kasus 3}

Nilai aliran daya terbesar yang mengalir pada saluran transmisi Sumatera Utara 2020 untuk kasus beban dasar berada di saluran 29 yaitu antara bus Sei Rotan - bus Titi Kuning sebesar 306,9 MW. Pada simulasi transien ini saluran ganda lepas tanpa adanya gangguan. Untuk hasil simulasinya sebagai berikut.

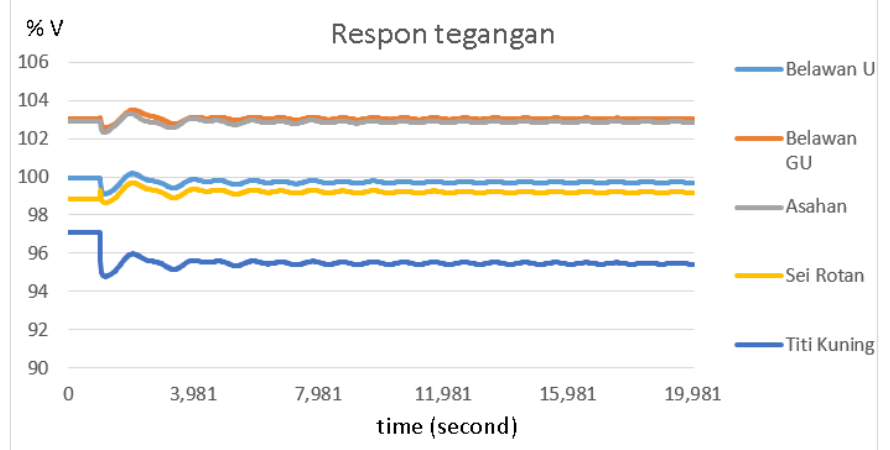

Gambar 4 Respon tegangan pada bus ketika saluran 29 lepas (2020 - peak load)

Dari hasil simulasi di atas, hilangnya saluran ganda (double circuit) tidak berdampak besar pada kestabilan sistem Transmisi Sumatera Utara khususnya pada tegangan di bus. Ketika saluran ganda lepas, osilalasi yang terjadi mengalami 
kenaikan hingga 103\% dan turun hingga 95\%. Setelah itu respon tegangan steady state pada $103 \%$ untuk bus PLTGU Belawan dan 95\% untuk bus Sei Rotan. Kita ketahui bahwa batas stabil untuk tegangan di Sistem Transmisi $150 \mathrm{kVadalah}$ 105\% dan 90\%. Jadi sistem Transmisi Sumatera Utara masih berada pada batas stabil ketika terjadi gangguan saluran ganda lepas.

\section{Simulasi Kasus 4}

Pada kasus ini, gangguan yang disimulasikan adalah gangguan satu fasa ke tanah pada bus, kemudian diikuti lepasnya satu saluran (saluran tunggal) dari saluran ganda

Pada tahun 2020 beban dasar, lokasi gangguan berada pada bus Sarulla. Kemudian saluran 199-1 yang menghubungkan bus Sarulla ke Batang Toru mengalami trip saluran tunggal pada detik $200 \mathrm{~ms}$ setelah gangguan. $300 \mathrm{~ms}$ kemudian saluran tunggal akan terhubung kembali. Untuk hasil simulasinya sebagai berikut.:

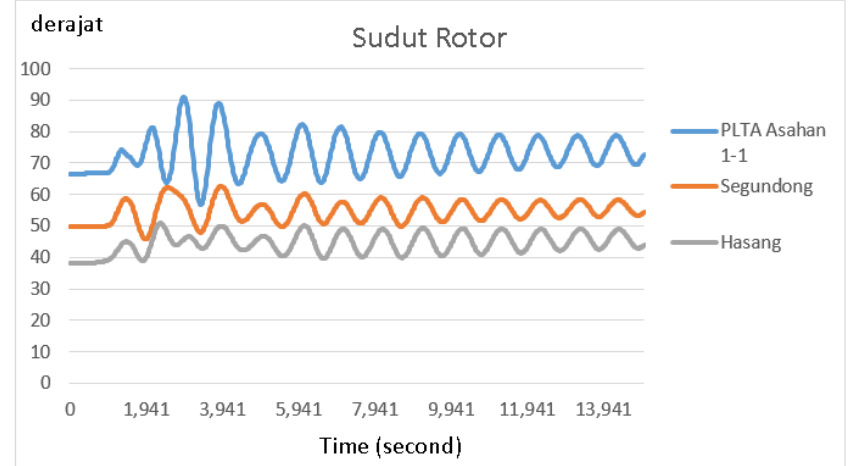

Gambar 5 Respon sudut Rotor Generator ketika kasus single pole auto reclosing di bus Sarulla (2020 - light load)

Pada hasil simulasi single pole auto reclosing, semua respon sudut rotor untuk ketiga Generator masih dalam kondisi stabil. Respon sudut rotor pada. PLTA Asahan mengalami osilasi sampai 90 degree namun bisa kembali lagi hingga steady state pada 70 - 80 degree. Sehingga sistem 2018 beban dasar masih dalam batas stabil saat terjadi gangguan 1 fasa dengan diikuti lepasnya saluran tunggal pada saluran ganda yang menghubungkan 2 bus hingga saluran tunggal terhubung kembali.

\section{E. Simulasi Kasus 5}

Pada kasus ini, gangguan yang disimulasikan adalah gangguan hubung singkat 3 fasa. Gangguan hubung singkat 3 fasa ini dipilih secara acak, kemudian diikuti dengan lepasnya saluran tunggal ( one circuit) dari saluran ganda.Waktu membukanya CB pada saluran tunggal saat sistem masih stabil hingga sistem tidak stabil disebut critical clearing time. Untuk mendapatkan nilai CCT metode yang dilakukan adalah metode "trial and error". Hasil Critical Clearing Time (CCT) dan Simulasi akan adalah sebagai berikut :

Tabel 1

Nilai CCT pada bus saluran Paya Geli - Batu Gingging

\begin{tabular}{ccc}
\hline \hline Tahun sistem & $\begin{array}{c}\text { Waktu stabil } \\
\text { (mili detik) }\end{array}$ & $\begin{array}{c}\text { Waktu tidak stabil } \\
\text { (mili detik) }\end{array}$ \\
\hline 2018 (peak) & 126 & 127 \\
$\mathbf{2 0 1 8}$ (light) & 396 & 397 \\
$\mathbf{2 0 2 0}$ (peak) & 799 & 800 \\
$\mathbf{2 0 2 0}$ (light) & 593 & 594 \\
\hline \hline
\end{tabular}

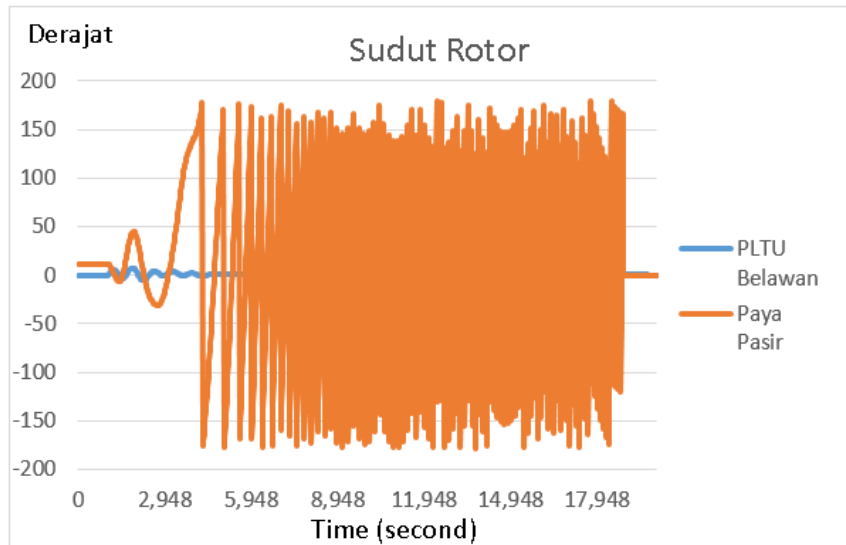

Gambar 6 Respon sudut rotor di generator ketika terjadi gangguan 3 fasa di saluran 166 yaitu antara bus Paya Geli dan Batu Gingging saat kondisi tidak stabil pada detik ke 0,127 setelah gangguan (2018-peak load)

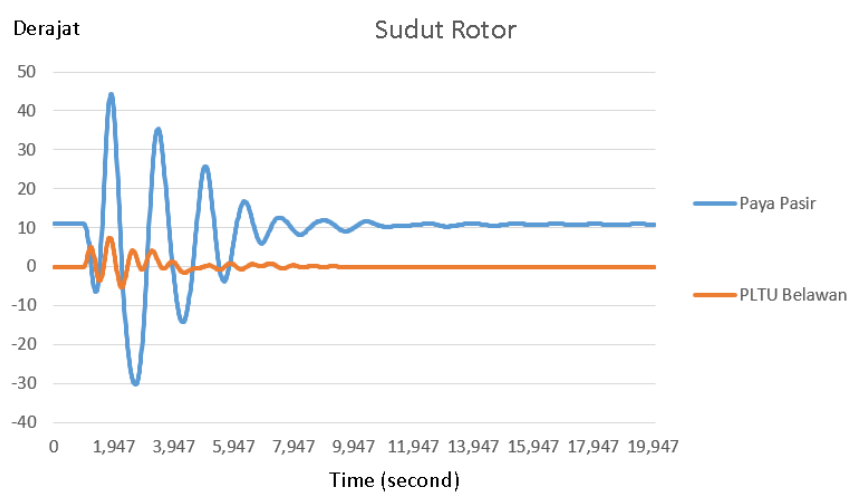

Gambar 7 Respon sudut rotor di generator ketika terjadi gangguan 3 fasa di saluran 166 yaitu antara bus Paya Geli dan Batu Gingging saat kondisi stabil pada detik ke 0,126 setelah gangguan (2018 - peak load)

Berdasarkan gambar hasil simulasi di atas, dari tahun 2018 peak hingga 2020 light perubahan kondisi stabil dan tidak stabil pada sistem selisih 0,001 detik. Yang artinya hanya berjarak 0,001 detik kondisi yang awalnya tidak stabil erubah menjadi stabil. Terlihat jelas pada perubahan sudut rotor generator Paya Pasir. Saat kondis tidak stabil, sudut rotor mengalami osilasi hingga $170-180$ degree. Setelah pada kondisi stabil, osilasi tertinggi sudut rotor Generator Paya Pasir 68 degree. Dan stabil pada 10 - 30 degree Pada sistem tahun 2018 beban puncak, nilai CCT berada dalam range rekomendasi waktu pemutusan kritis untuk sistem transmisi yaitu $120 \mathrm{~ms}-140 \mathrm{~ms}$. Sedangkan pada sisem tahun 2018 beban dasar dan tahun 2020 waktu pemutusan kritsnya melebihi dari range rekomendasi.

\section{KESIMPULAN}

Dari hasil simulasi dan analisis, maka dalam Tugas Akhir ini dapat ditarik kesimpulan bahwa:

1. Dari kasus Generator lepas dan saluran lepas, sistem masih dalam batas stabil. Karena saat salah satu generator lepas, sistem Sumatera Utara hanya kehilangan $5-8 \%$ daya supply pada sistem. Meskipun pada saat PLTA Batang Toru mengalami kenaikan sudut rotor yang hampir mencapai batas kestabilan yaitu 80,3 degree. 
2. Dari kasus Single Pole Auto Reclosing, sistem juga masih dalam kondisi stabil dengan waktu line reclosed $500 \mathrm{~ms}$ setelah gangguan.

3. Pada sistem 2018 beban puncak maupun beban dasar, nilai Critical Clearing Time yang didapat adalah $126 \mathrm{~ms}-127$ ms untuk beban puncak, dan 396 ms -397 ms untuk beban dasar. Sedangkan untuk sistem 2020 adalah 799 ms - 800 ms untuk beban puncak, dan 593 ms - 594 ms. Namun batas membukanya CB dengan cepat untuk sistem transmisi adalah $120 \mathrm{~ms}-140 \mathrm{~ms}$. Sehingga untuk sistem 2018 beban dasar dan sisem tahun 2020 tidak direkomendasikan untuk menggunakan waktu CCT sesuai hasil simulasi.

\section{DAFTAR PUSTAKA}

[1]Imam Robandi, Margo Pujiantara, "Analisa Sistem Tenaga Modern [Pengantar stabilitas Dinamik]" Proyek PercepatanPendidikan Insinyur th 1996/1997 FTI ITS, 1997.

[2]Kundur, P., "Power System Stability and Control", McGraw-Hill, Inc, 1994.

[3] Stevenson, W.D., Jr and John J. Grenger, "Elements of Power System Analysis, 4th Edition". McGraw-Hill, Inc, 1994

[4]IEEE/CIGRE Joint Task Force on Stability Terms and Definitions, "Definition and Classification of Power System Stability"IEEE Transactions on Power system, vol. 19, no. 2, may 2004. 